\title{
COMPARISON OF SURFACE ROUGHNESS OF COLDWORK AND HOT WORK TOOL STEELS IN HARD TURNING
}

\author{
Varaprasad. $\mathrm{Bh}^{1 *}$, Srinivasa Rao. $\mathrm{Ch}^{2}$ \\ 1*Mechanical Engineering Department, GVP College for Degree and P.G. Courses, \\ School of Engineering (Technical Campus), Rushikonda, Visakhapatnam, India \\ ${ }^{2}$ Mechanical Engineering Department, Andhra University, College of Engineering (A) \\ Visakhapatnam, India.
}

\begin{abstract}
The hard turning process has been attracting interest in different industrial sectors for finishing operations of hard materials at its hardened state.Surface roughness is investigated in hard turning of AISI D3 and AISI H13 steels of same hardness 62HRC. In this paper, an attempt has been made to model and predict the surface roughness in hard turning of AISI D3 and AISI H13 hardened steels using Response Surface Methodology (RSM). The combined effects of three machining parameters such as cutting speed, feed rate and depth of cut are investigated for main performance characteristic that is surface roughness. RSM based Central Composite Design (CCD) is applied as an experimental design. $\mathrm{Al}_{2} \mathrm{O}_{3} /$ TiC mixed ceramic tool with corner radius $0.8 \mathrm{~mm}$ is employed to accomplish 20 tests with six center points. The acceptability of the developed models is checked using Analysis of Variance (ANOVA).The combined effects of cutting speed; feed rate and depth of cut are investigated using surface plots.
\end{abstract}

\section{Key words:}

Hard turning, Surface Roughness, AISI D3, AISI H13, RSM and ANOVA.

\section{INTRODUCTION}

Hard turning is the process of single point cutting of hardened ferrous material with a hardness value more than $45 \mathrm{HRC}$ in order to obtain finished workpieces directly from hardened parts [15]. Hardened steels are most widely used in multiple industrial applications like automotive, aeronautics, tool design and mold design.Many industrial steel components under influence of critical loads from automotive and aerospace parts to bearing and forming tool are made of hardened steel. These parts are normally finished by grinding, which is time consuming and costly. For this reason, hard turning has become the most important substitute to grinding for hardened steels $[6,7]$.With advent of new kind of tools such as Cubic Boron Nitride (CBN), Polycrystalline Cubic Boron Nitride (PCBN), poly-crystalline diamond (PCD), coated, Chemical Vapor Deposition (CVD), Physical Vapor Deposition (PVD) and ceramic tools, better surface finish will be accessible without any finishing and complementary operation such as grinding. Reduction in machining costs, elimination of cutting fluids, increase in the flexibility and efficiency, reduction in part-handling costs and finally decrease in the set-up times when compared to grinding process are the advantages of hard turning [1,4]. Achieving better surface quality, tool life and dimensional accuracy are of crucial concerns in turning of hardened steels [4]. The major focus of present research is on surface roughness of the machined surfaces and it is one of the most important product quality characteristics. Achieving the suitable surface quality 
in hard turning especially in comparison with grinding is of great importance to the functional behavior of a machined part. Very few studies are reported on hard turning of AISI D3 with ceramic tool and also comparison of machining of both AISI D3 and AISI H13. The main scope of the present research is the experimental investigation of the effect of machining parameters (i.e., cutting speed, feed rate, depth of cut) on surface roughness in hard turning process of AISI D3 and AISI H13. In this experimental work, ANOVA is used to know the percentage of contribution of each parameter on performance. To analyze the effect of process parameters on surface roughness by plotting main effects graph and their individual interactions. Moreover, RSM and regression analysis are used to establish the correlation between factors and responses.

$\mathrm{Al}_{2} \mathrm{O}_{3} / \mathrm{TiN}$-coated tungsten carbide tools for finish-turning of NiCr20TiAl nickel-based alloy under various cutting conditions, cutting forces, surface integrity and tool wear are investigated and the inter-diffusing and transferring of elements between $\mathrm{Al}_{2} \mathrm{O}_{3} /$ TiN-coated tungsten carbide tool and NiCr20TiAl nickel-based alloy are studied [8]. Investigated the cutting performance of tungsten carbide tools with restricted contact length and multilayer chemical vapor deposition coatings, $\mathrm{TiCN} / \mathrm{Al}_{2} \mathrm{O}_{3} / \mathrm{TiN}$ and $\mathrm{TiCN} / \mathrm{Al}_{2} \mathrm{O}_{3}-\mathrm{TiN}$ in dry turning of AISI 4140 and the results show that coating layouts and cutting tool edge geometry can significantly affect heat distribution into the cutting tool [9]. Presented an optimization method of the machining parameters in high-speed machining of stainless steel using coated carbide tool to achieve minimum cutting forces and better surface roughness using Taguchi's technique and pareto ANOVA and found that the feed rate is found to be more significant followed by the cutting speed and the depth of cut [10].

A method developed to identify surface roughness based on measurement of workpiece surface temperature and root mean square for feed vibration of the cutting tool during turning mild steel using grey relational analysis [11]. Machinability of hardened steel using grey relational approach and ANOVA to obtain optimum process parameters considering MRR, surface finish, tool wear and tool life for both rough and finish machining [12]. Multi-response optimization of turning parameters and nose radius over surface roughness and power consumed using Taguchi based grey relational approach and found that the main influencing parameter is cutting speed followed by feed rate and depth of cut [13]. In turning operations, for multi-response optimization Taguchi based grey relational approach is used to identify the optimum conditions to obtain better results $[14,15]$. Prediction of flank wear and surface roughness during hard turning is performed using uncoated carbide inserts of various tool geometries [16].

\section{Experimentation}

The materials used for experiments are AISI D3 and AISI H13. Bars of diameter $70 \mathrm{~mm} \times 360$ $\mathrm{mm}$ long are prepared. Test sample is trued, centred and cleaned by removing a $2 \mathrm{~mm}$ layer prior to actual machining tests. The chemical composition of the work piece materials are given in Table. 1 and Table.2.The AISI D3 is oil-quenched from $980^{\circ} \mathrm{C}\left(1800^{\circ} \mathrm{F}\right)$ for hardening, followed by tempering at $200^{\circ} \mathrm{C}$ to attain $62 \mathrm{HRC}$. The AISI $\mathrm{H} 13$ is hardened by oil quenching from $1050^{\circ} \mathrm{C}$ and tempered at $600^{\circ} \mathrm{C}$ to attain $62 \mathrm{HRC}$.

Table.1 Chemical composition of AISI D3 (wt \%)

\begin{tabular}{|l|l|l|l|l|l|l|l|l|l|l|l|}
\hline $\mathbf{C}$ & $\mathbf{S i}$ & $\mathbf{M n}$ & $\mathbf{P}$ & $\mathbf{S}$ & $\mathbf{C r}$ & $\mathbf{N i}$ & $\mathbf{M o}$ & $\mathbf{A l}$ & $\mathbf{C u}$ & $\mathbf{Z n}$ & $\mathbf{F e}$ \\
\hline 2.06 & 0.55 & 0.449 & 0.036 & 0.056 & 11.09 & 0.277 & 0.207 & 0.0034 & 0.13 & 0.27 & 84.8716 \\
\hline
\end{tabular}

Table.2 Chemical composition of AISI H13 (wt\%)

\begin{tabular}{|l|l|l|l|l|l|l|l|l|l|}
\hline $\mathbf{C}$ & $\mathbf{S i}$ & $\mathbf{M n}$ & $\mathbf{P}$ & $\mathbf{S}$ & $\mathbf{C r}$ & $\mathbf{N i}$ & $\mathbf{M o}$ & $\mathbf{V}$ & $\mathbf{F e}$ \\
\hline 0.4 & 1.05 & 0.35 & 0.03 & 0.003 & 5.03 & 0.3 & 1.4 & 1.0 & 90.437 \\
\hline
\end{tabular}


The lathe used for machining operations is Kirloskar; model Turn Master-35, spindle power 6.6KW.Surface roughness is measured using MitutoyoSurftest SJ 210 having measuring range of $17.5 \mathrm{~mm}$ and skid force less than $400 \mathrm{mN}$. Four readings with a sample length of $0.8 \mathrm{~mm}$ are recorded after each experiment and an average value is taken as the surface roughness. These values are obtained without disturbing the assembly of the workpiece in order to reduce uncertainties.

The cutting insert used is a mixed ceramic removable, of square form with eight cutting edges and having designation SNGA 120408 T01020 (Sandvik make CC6050) is a mixed ceramic grade based on alumina with an addition of titanium carbide. The high hot-hardness, the good level of toughness makes the grade suitable as first choice for machining hardened steels $(50-$ 65HRC) in applications with good stability or with light interrupted cuts. The inserts are mounted on a commercial tool holder of designation PSBNR $2525 \mathrm{M} 12$ (ISO) with the geometry of active part characterized by the following angles: $\chi=75^{\circ} ; \alpha=6^{\circ} ; \gamma=-6^{\circ} ; \lambda=-6^{\circ}$. Three levels are defined for each cutting variable as given in Table.3. The variable levels are chosen within the intervals according to recommendations made by the cutting tool manufacturer. Three selected cutting variables at three levels led to a total of 20 tests.

Table.3. Assignment of the levels to the variables

\begin{tabular}{|l|l|l|l|}
\hline \multirow{2}{*}{ Parameters } & \multicolumn{3}{|c|}{ Range } \\
\cline { 2 - 4 } & \multicolumn{2}{|c|}{-1} & \multicolumn{1}{|c|}{+1} \\
\hline Speed(m/min) & 145 & 155 & 165 \\
\hline Feed(mm/rev) & 0.05 & 0.075 & 0.1 \\
\hline Depth of cut(mm) & 0.3 & 0.6 & 0.9 \\
\hline
\end{tabular}

\section{ANALYSIS OF RESULTS}

The analysis is made by considering experimental results of surface roughness $\left(\mathrm{R}_{\mathrm{a}}\right)$ for various combinations of cutting conditions (cutting speed, feed rate and depth of cut) as per the design matrix. Data is analyzed statistically usingANOVA, Contour plots and Surface plots are shown and discussed in the following sections.

\subsection{Statistical Analysis}

In RSM, the quantitative form of the relationship between the desired response and independent input process parameters can be represented by [17].

$Y=\emptyset\left(V_{c}, f, a_{p}\right)$

Where $\mathrm{Y}$ is the desired response and $f$ is the response function. In the present investigation, the RSM-based mathematical model for surface roughness Ra, has been developed with cutting speed $\mathrm{Vc}$, feed rate $\mathrm{f}$ and depth of cut $\mathrm{a}_{\mathrm{p}}$ as the process parameters. The response surface equation for three factors is given by [17].

$$
\begin{gathered}
Y=a_{0}+a_{1} V_{c}+a_{2} f+a_{3} a_{p}+a_{12} V_{c} f+a_{13} V_{c} a_{p}+a_{23} f a_{p}+a_{11} V_{c}^{2}+a_{22} f^{2}+ \\
a_{33} a_{p}^{2}(2)
\end{gathered}
$$

Where Y; desired response and $a_{1}, \ldots \ldots \ldots . . . ., a_{33}$; regression coefficients to be determined for each response. The estimated Regression Coefficients for surface roughness of AISI D3 and AISI H13 for surface roughness Ra are shown in Table.4 and 5. 
International Journal of Recent advances in Mechanical Engineering (IJMECH) Vol.4, No.1, February 2015

Table.4. Estimated Regression Coefficients for surface roughness of AISI D3R $\mathrm{R}_{\mathrm{a}}$ (microns)

\begin{tabular}{|c|c|c|c|c|c|}
\hline Term & Coef & SE Coef & $\mathrm{T}$ & $\mathrm{P}$ & Remarks \\
\hline Constant & -16.55 & 29.814 & -0.555 & 0.591 & Insignificant \\
\hline Speed(m/min) & 0.27 & 0.39 & 0.69 & 0.506 & Insignificant \\
\hline Feed(mm/rev) & -121.55 & 54.994 & -2.21 & 0.049 & Significant \\
\hline $\mathrm{DOC}(\mathrm{mm})$ & 5.27 & 4.22 & 1.248 & 0.241 & Insignificant \\
\hline Speed $(\mathrm{m} / \mathrm{min}) \times \mathrm{Speed}(\mathrm{m} / \mathrm{min})$ & 0 & 0.001 & -0.548 & 0.595 & Insignificant \\
\hline Feed(mm/rev) x Feed(mm/rev) & 1185.16 & 200.614 & 5.908 & 0.000 & Significant \\
\hline $\mathrm{DOC}(\mathrm{mm}) \times \mathrm{DOC}(\mathrm{mm})$ & -0.35 & 1.393 & -0.249 & 0.808 & Insignificant \\
\hline Speed $(\mathrm{m} / \mathrm{min}) \times$ Feed $(\mathrm{mm} / \mathrm{rev})$ & -0.48 & 0.294 & -1.639 & 0.132 & Insignificant \\
\hline Speed $(\mathrm{m} / \mathrm{min}) \times \mathrm{DOC}(\mathrm{mm})$ & -0.03 & 0.025 & -1.102 & 0.296 & Insignificant \\
\hline Feed(mm/rev) x DOC $(\mathrm{mm})$ & -5.62 & 9.802 & -0.573 & 0.579 & Insignificant \\
\hline
\end{tabular}

$R_{a}=-16.55+0.27 \times X_{1}-121.55 \times X_{2}+5.27 \times X_{3}+1185.16 \times X_{2}^{2}$

Where $X_{1}, X_{2}$ and $X_{3}$ Speed, Feed and Depth of cut.

Table.5. Estimated Regression Coefficients for surface roughness of AISI H13 $\mathrm{R}_{\mathrm{a}}$ (microns)

\begin{tabular}{|c|c|c|c|c|c|}
\hline Term & Coef & SE Coef & $\mathrm{T}$ & $\mathrm{P}$ & Remarks \\
\hline Constant & 73.6655 & 29.541 & 2.494 & 0.032 & Significant \\
\hline Speed $(\mathrm{m} / \mathrm{min})$ & -0.9472 & 0.386 & -2.453 & 0.034 & Significant \\
\hline Feed $(\mathrm{mm} / \mathrm{rev})$ & 55.0202 & 54.49 & 1.01 & 0.336 & Insignificant \\
\hline $\mathrm{DOC}(\mathrm{mm})$ & -7.497 & 4.181 & -1.793 & 0.103 & Insignificant \\
\hline Speed $(\mathrm{m} / \mathrm{min}) \times \operatorname{Speed}(\mathrm{m} / \mathrm{min})$ & 0.003 & 0.001 & 2.446 & 0.034 & Significant \\
\hline Feed $(\mathrm{mm} / \mathrm{rev})$ x Feed $(\mathrm{mm} / \mathrm{rev})$ & 37.0473 & 198.776 & 0.186 & 0.856 & Insignificant \\
\hline $\mathrm{DOC}(\mathrm{mm}) \times \mathrm{DOC}(\mathrm{mm})$ & -0.2316 & 1.38 & -0.168 & 0.87 & Insignificant \\
\hline Speed $(\mathrm{m} / \mathrm{min}) \times$ Feed $(\mathrm{mm} / \mathrm{rev})$ & -0.3428 & 0.291 & -1.176 & 0.267 & Insignificant \\
\hline Speed(m/min) x DOC $(\mathrm{mm})$ & 0.0611 & 0.024 & 2.515 & 0.031 & Significant \\
\hline Feed(mm/rev) x DOC(mm) & -13.3917 & 9.712 & -1.379 & 0.198 & Insignificant \\
\hline
\end{tabular}

$R_{a}=73.66-0.94 \times X_{1}+55.02 \times X_{2}-7.49 \times X_{3}+0.003 \times X_{1}^{2}+0.0611 \times\left(X_{1} \times X_{2}\right)$

Where $X_{1}$ is Speed, $X_{2}$ is Feed and $X_{3}$ is Depth of cut.

Scatter plots identifies the relationship between two variables whether the relationship is positive, negative, or no relationship can be easily detected. It can be observed from figure.1 the residuals are located on straight line, which means that the errors are distributed normally. Hence the developed empirical models can represent the process significantly. Therefore these models can be further used for optimization of process parameters such as speed, feed and depth of cut. 


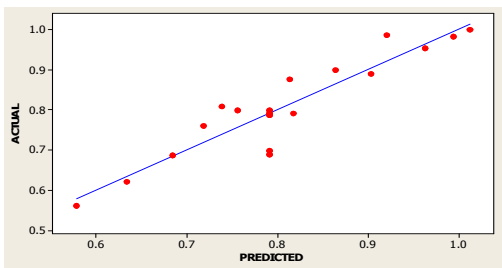

Fig.3a. Ra of AISI D3

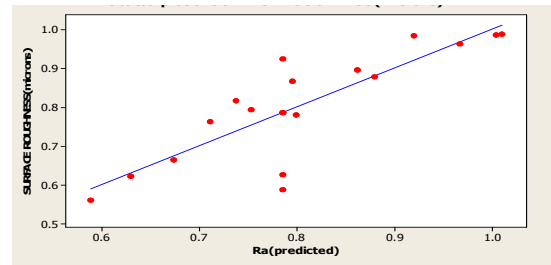

Fig.3b. Ra of AISI H13

Fig 1. Scatter plots for actual and predicted values of $\mathrm{R}_{\mathrm{a}}$ of AISI D3 and AISI H13steels

\subsection{Analysis of Variance}

It is clear from the results of ANOVA that the feed is the dominant factor affecting surface finish $\mathrm{Ra}$. The second factor influencing $\mathrm{Ra}$ is cutting speed $\mathrm{x}$ feed for AISI D3 shown in table.6. Table.7.shown below is ANOVA for AISI H13.To understand the hard turning process in terms of surface roughness $\mathrm{Ra}$, mathematical modelsare developed using multiple regression method. $\mathrm{Ra}$ models are given by equations (3\&4). Its coefficient of correlation $\mathrm{R}^{2}$ is 92.8 for AISI D3 and its value 75.87 for AISI H13.

The ANOVA has been applied to check the adequacy of the developed models. The ANOVA table consists of sum of squares and degrees of freedom. The sum of squares is performed into contributions from the polynomial model and the experimental value and was calculated by the following equation (5):

$$
S S_{f}=\frac{N}{N_{n_{f}}} \sum_{i=1}^{N_{n_{f}}}\left(\overline{y_{l}}-\bar{y}\right)^{2}(5)
$$

The mean square is the ratio of sum of squares to degrees of freedom was calculated by the following equation(6):

$$
M S=\frac{M S_{i}}{D F_{i}}
$$

F-value is the ratio of mean square of regression model to the mean square of the experimental error was calculated by the following equation(7):

$F-$ value $=\frac{M S_{i}}{M S_{\text {error }}}$

This analysis was out for a $5 \%$ significance level, i.e., for a $95 \%$ confidence level. The percentage of each factor contribution (Cont. \%) on the total variation, then indicating the degree of influence on the result, was calculated by the following equation (8) :

$$
\text { cont. } \%=\frac{S S_{i}}{S S_{\bmod }} X 100(8)
$$

A low P-value indicates statistical significance for the source on the corresponding response. It is clear from the results of ANOVA that the depth of cut is the dominant factor affecting surface finish. To understand the hard turning process in terms of surface roughness Ra, mathematical model is developed using multiple regression method. Ra model is given by equations 1 and 2. Its coefficient of correlation $\mathrm{R}^{2}$ is $92.80 \%$ for AISI D3 steel and $75.87 \%$ for AISI H13 steel. 
Table.6. Analysis of Variance for surface roughness AISI D3

\begin{tabular}{|l|c|c|c|c|c|c|}
\hline Source & DF & Seq SS & Adj SS & Adj MS & F & P \\
\hline Regression & 9 & 5.5737 & 5.5737 & 0.6193 & 14.32 & 0 \\
\hline Speed(mm/min) & 1 & 0.01166 & 0.0206 & 0.0206 & 0.48 & 0.506 \\
\hline Feed(mm/rev) & 1 & 2.98608 & 0.21121 & 0.21121 & 4.89 & 0.049 \\
\hline DoC(mm) & 1 & 0.05293 & 0.06731 & 0.06731 & 1.56 & 0.241 \\
\hline Speed(mm/min)*Speed(mm/min) & 1 & 0.63689 & 0.01301 & 0.01301 & 0.3 & 0.595 \\
\hline Feed(mm/rev)*Feed(mm/rev) & 1 & 1.70061 & 1.50886 & 1.50886 & 34.9 & 0.000 \\
\hline DoC(mm)*DoC(mm) & 1 & 0.00269 & 0.00269 & 0.00269 & 0.06 & 0.808 \\
\hline Speed(mm/min)*Feed(mm/rev) & 1 & 0.11616 & 0.11616 & 0.11616 & 2.69 & 0.132 \\
\hline Speed(mm/min)*DoC(mm) & 1 & 0.05249 & 0.05249 & 0.05249 & 1.21 & 0.296 \\
\hline Feed(mm/rev)*DoC(mm) & 1 & 0.0142 & 0.0142 & 0.0142 & 0.33 & 0.579 \\
\hline Residual Error & 10 & 0.43233 & 0.43233 & 0.04323 & & \\
\hline Total & 19 & 6.00603 & & & & \\
\hline
\end{tabular}

Table.7. Analysis of Variance for surface roughness Ra of AISI H13

\begin{tabular}{|l|c|c|c|c|c|c|}
\hline Source & DF & Seq SS & Adj SS & Adj MS & F & P \\
\hline Regression & 9 & 1.33475 & 1.33475 & 0.148306 & 3.49 & 0.032 \\
\hline Speed(mm/min) & 1 & 0.03405 & 0.25548 & 0.255479 & 6.02 & 0.034 \\
\hline Feed(mm/rev) & 1 & 0.00213 & 0.04327 & 0.043274 & 1.02 & 0.336 \\
\hline DoC(mm) & 1 & 0.42271 & 0.13644 & 0.136442 & 3.21 & 0.103 \\
\hline Speed(mm/min)*Speed(mm/min) & 1 & 0.46601 & 0.25398 & 0.253984 & 5.98 & 0.034 \\
\hline Feed(mm/rev)*Feed(mm/rev) & 1 & 0.00075 & 0.00147 & 0.001474 & 0.03 & 0.856 \\
\hline DoC(mm)*DoC(mm) & 1 & 0.00119 & 0.00119 & 0.001195 & 0.03 & 0.870 \\
\hline Speed(mm/min)*Feed(mm/rev) & 1 & 0.05874 & 0.05874 & 0.058739 & 1.38 & 0.267 \\
\hline Speed(mm/min)*DoC(mm) & 1 & 0.26846 & 0.26846 & 0.268461 & 6.33 & 0.031 \\
\hline Feed(mm/rev)*DoC(mm) & 1 & 0.08070 & 0.08070 & 0.080702 & 1.90 & 0.198 \\
\hline Residual Error & 10 & 0.42444 & 0.42444 & 0.042444 & & \\
\hline Total & 19 & 1.75919 & & & & \\
\hline
\end{tabular}

\subsection{Contour Plots for Surface Roughness Vs Speed, Feed and Depth of cut.}

Contour plots play a very important role in the study of the response surface. By creating contour plots using software for response surface analysis, the optimum is located by characterizing the shape of the surface. Circular shaped contour represents the independence of factor effects and elliptical contours may indicate factor interaction. The contours of AISI D3 and AISI H13 responses are shown in figure.2. (a-f).The surface roughness is clearly shown that minimum roughness is at low value of feed, because feed is the most influencing factor for surface roughness. Ra is minimum at low depth of cut and also at low speed. 

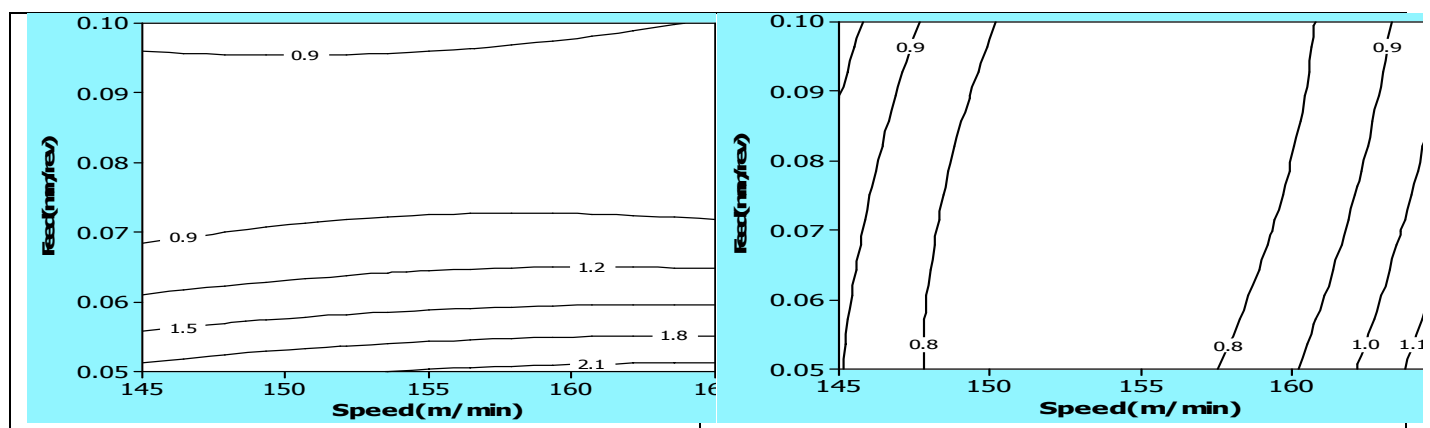

Fig.2a.R $\mathrm{R}_{\mathrm{a}}$ vs Speed andFeed(AISI D3)

Fig.2b. $\mathrm{R}_{\mathrm{a}}$ vsFeed and Speed(AISI H13)
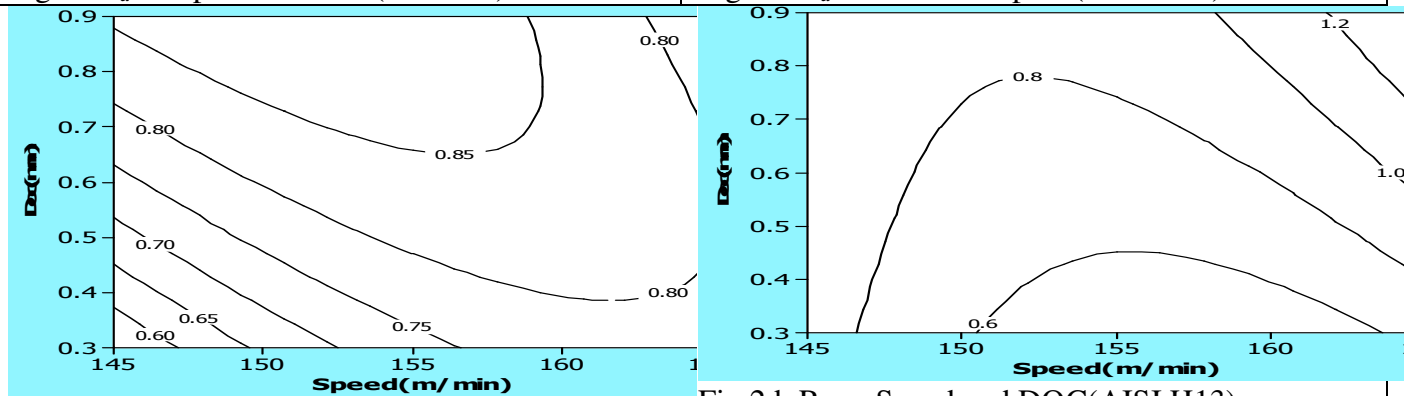

Fig.2c. $R_{a}$ vs Speed andDOC (AISI D3)

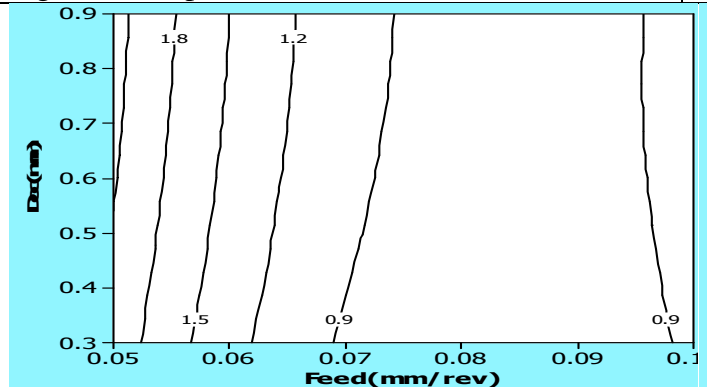

Fig.2d. $\mathrm{R}_{\mathrm{a}}$ vs Speed and DOC(AISI H13)

Fig.2e. $R_{\mathrm{a}}$ vs DOC and Feed (AISI D3)

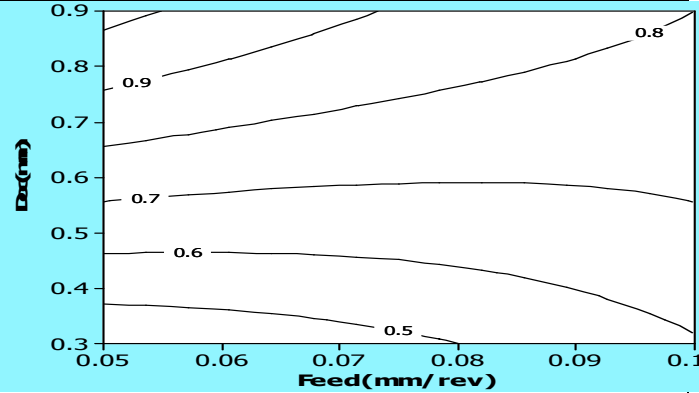

Fig.2f. $\mathrm{R}_{\mathrm{a}}$ vs DOC and Feed (AISI H13)

Fig. 2. Contour plots for AISI D3 and AISI H13

\subsection{D Surface plots}

3D Surface plots of Ra vs. different combinations of cutting parameters are shown in figure 3a, 3c, 3e for AISI D3 and these figures obtained by RSM Fig. 3(a) presents the influences of cutting speed $(\mathrm{Vc})$ and feed rate (f) on the surface roughness, while the depth of cut $\left(\mathrm{a}_{\mathrm{p}}\right)$ is kept at the middle level. Fig.3(c) shows the estimated response surface in relation to the cutting speed (Vc) and depth of cut $\left(a_{p}\right)$, while feed rate (f) is kept at the middle level. The effects of the feed rate (f) and depth of cut $\left(a_{p}\right)$ on the surface roughness components are shown in Fig. 3(e), while the cutting speed $(\mathrm{Vc})$ is kept at the middle level. For each plot, the variables not represented are held at a constant value (the middle level) for AISI D3. For AISI H13 figures shown in 3b, $3 \mathrm{~d}$ and 3f.These 3D plots confirm the nodes observed during the principal effects plots analysis. 


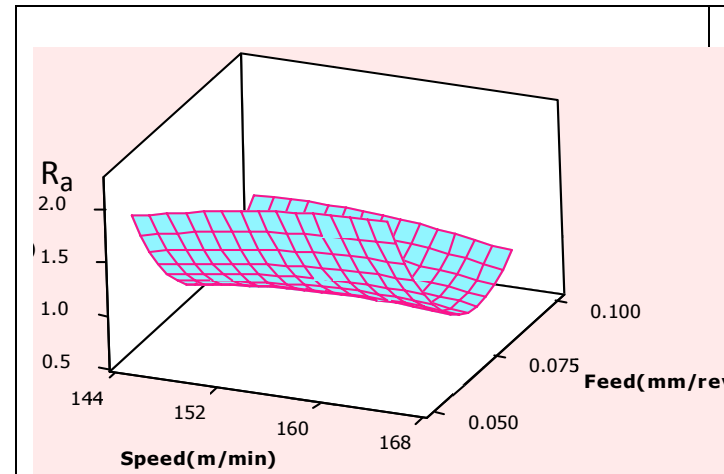

Fig.3a. Surface roughness vs Speed and Feed (AISI D3)

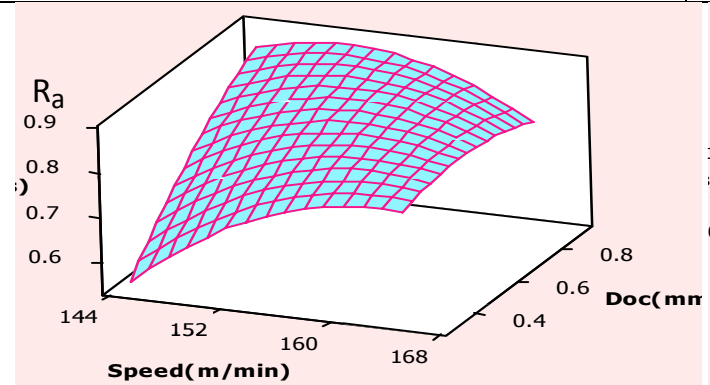

Fig.3c. Surface roughness vs Speed and DOC (AISI D3)

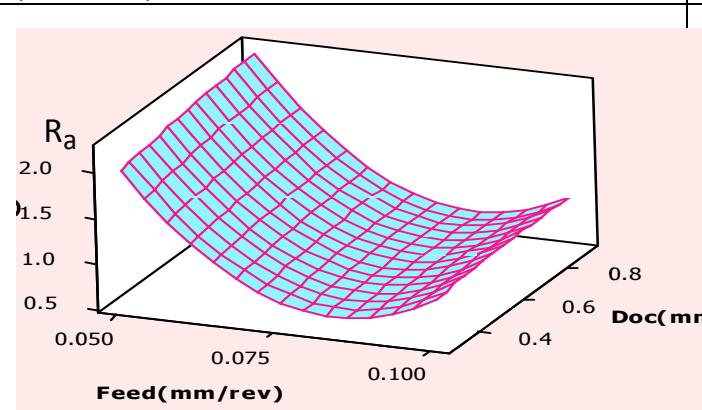

Fig.3e. Surface roughness Vs Feed and Depth of cut(AISI D3)

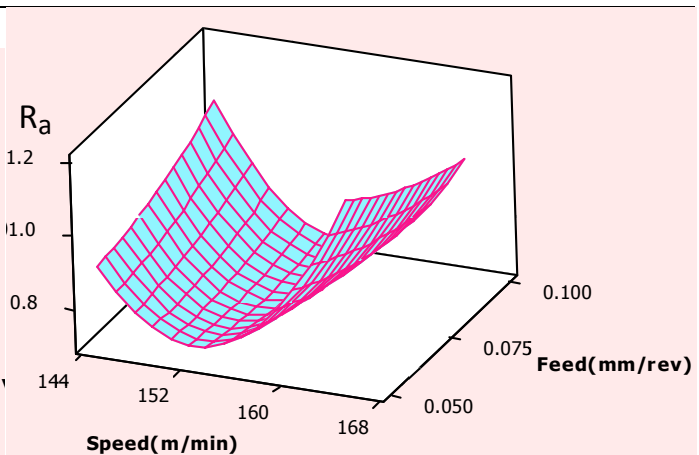

Fig. 3b. Surface roughness vs Speed and Feed (AISI H13)

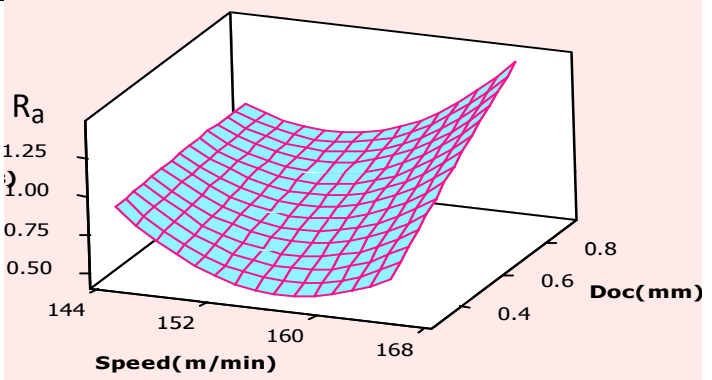

Fig. 3d.Surface roughness vs Depth of cut and Speed(AISI H13)

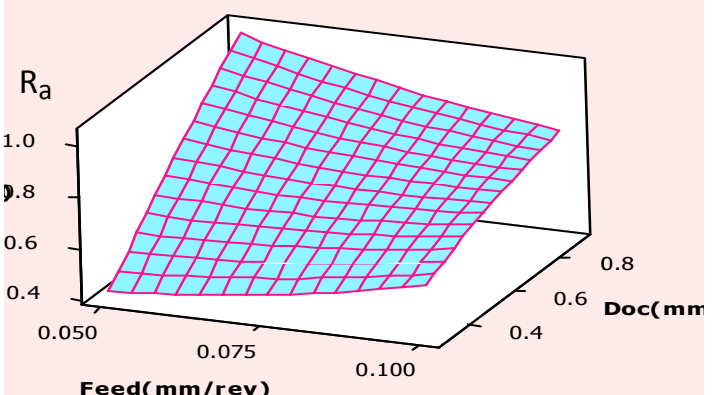

Fig. 3f.Surface roughness vs Feed and DOC(AISI H13)

Fig. 3. Surface Plots for AISI D3 and AISI H13

\section{Conclusions}

The tests of straight turning carried out on AISI D3 and AISI H13 steels treated at 62 HRC, machined by a mixed ceramic tool enabled us to develop statistical models of surface roughness criteria.

$>$ The results revealthat the feed rate isthe most influencing parameter on surface roughness, than cutting speed and depth of cut for AISI D3.

$>$ Surface roughness AISI H13 is influenced mostly by cutting speed than the other parameters such as feed rate and depth of cut.

$>$ Statistical models deduced defined degree of influence of each machining condition on surface roughness criteria. These models can also be used for the optimization of hard turning process. This study confirms that in dry hard turning of AISI D3 and 
AISI H13 steels for all cutting conditions tested and found roughness criteria are close to those obtained in grinding.

$>$ The surface roughness values of AISI D3 obtained higher when compared to AISI H13 for the same cutting conditions.

\section{References}

[1] Özel, T., and Karpat, Y., 2005, "Predictive Modeling of Surface Roughness and Tool Wear in Hard Turning Using Regression and Neural Networks", International Journal of Machine Tools and Manufacture, Vol.45, p.467-479.

[2] Zeren, E., and Özel, T,2002, "Hard Turning Technology", Report No. MARL-01, Rutgers, The State University of New Jersey.

[3] Koenig, W., Berktold, A., and Koch, F., 1993, "Turning Versus Grinding-A Comparison of Surface Integrity Aspects and Attainable Accuracies", Annals of the CIRP, Vol. 42(1), p. 39- 43.

[4] Mohammadi,A. and Zarepour,H., 2008, "Statistical Analysis Of Hard turning Of AISI 4340 Steel on surface finish and Cutting Region Temperature”, M0048010,Bahrain ,Manama, AMPT 2008.

[5] Kountanya, R.K., 2008, "Optimizing PCBN cutting tool performance in hard turning” ,Proceeding of the Institution of Mechanical Engineers, part B:Journal of Engineerin manufacture, Vol. 222, p. 969980.

[6] Dogra,M., Sharma,V.S., Sachdeva,A., Mohan suri,N. and Dureja,J.S, 2010, "Tool wear, Chip Formation and Workpiece Surface Issues In CBN Hard Turning:A Review”, Intetnational Journal of Pecision Engineering and Manufacturing,Vol.11,p. 341-358.

[7] Horng,J-T., Liu,N-M., Chiang, K-T., 2008, "Investigating the machinability evaluation of hodfield steel in the hard turning with A12O3/TiC mixed ceramic Tool based on the response surface methodology", Journal Of Materials Processing Technology, Vol. 208,p. 532-541.

[8] Zou B., Chen M., and Li S., 2011, "Study on finish-turning of NiCr20TiAl nickel-based alloy using Al2O3/TiNcoated carbide tools". International Journal of Advanced Manufacturing Technology, Vol.53, p.81-92

[9] Fahad M., Mativenga PT., and Sheikh MA., 2012,"A comparative study of multilayer and functionally graded coated tools in high-speed machining”, International Journal of Advanced Manufacturing Technology, Vol. 62, p. 43-57.

[10] Hamdan A., Sarhan AAD., and Hamdi M., 2012, "An optimization method of the machining parameters in high speed machining of stainless steel using coated carbide tool for best surface finish”, International Journal of Advanced Manufacturing Technology,Vol. 58, p.81-91.

[11] Suhail AH., Ismail N., Wong SV., and Jalil NAA., 2012,"Surface Roughness Identification Using the Grey Relational Analysis with Multiple Performance Characteristics in Turning operations", The Arabian Journal for Science and Engineering, Vol.37(4), p. 1111-1117

[12] Gopalsamy BM., Mondal B., and Ghosh S., 2009, "Optimisation of machining parameters for hard machining: grey relational theory approach and ANOVA". International Journal of Advanced Manufacturing Technology, Vol.45, p.1068-1086.

[13] Ahilan C., Kumanan S., and Sivakumaran N., 2010, "Application of Grey based Taguchi method in multi response optimization of turning process". Advances in Production Engineering \& Management, Vol. 5(3), p. 171- 180.

[14] Tzeng CJ., Lin YH., Yang YK., and Jeng MC.,2009,“Optimization of turning operations with multiple performance characteristics using the Taguchi method and Grey relational analysis", Journal of Materials Processing Technology, Vol.209, p. 2753-2759.

[15] Kazancoglu Y., Esme U., Bayramoglu M., Guven O., and Ozgun S., 2011, "Multi-Objective Optimization of The Cutting Forces In Turning Operations Using The Grey-Based Taguchi Method", Materials and Technology, Vol. 45(2), p. 105-110.

[16] Senthilkumar N., Tamizharasan T., and Anandakrishnan V.,2013, "An ANN approach for predicting the cutting inserts performances of different geometries in hard turning" Advances in Production Engineering \& Management, Vol. 8(4), p.231-241.

[17] Montgomery, D.C. "Design and Analysis of Experiments"; John Wiley \& Sons, Inc: New York, 1997; p. 395-476. 
International Journal of Recent advances in Mechanical Engineering (IJMECH) Vol.4, No.1, February 2015

\section{Authors:}

1) Varaprasad Bhemuni currently an Assistant. Professor in Mechanical Engineering Department at GVP Degree and PG Courses (Technical Campus), School of Engineering, Rushikonda, Visakhapatnam. He has more than 10 years teaching experience and worked at different positions. He has life member of many technical societies.

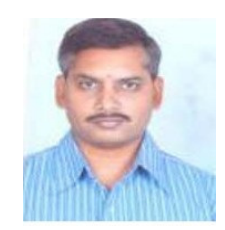

2) Chalamalasetti Srinivasa Rao is currently Professor in the Department of Mechanical Engineering, Andhra University, Visakhapatnam, India. He graduated in Mechanical Engineering from SVH Engineering College, Machilipatnam, India in 1988. He received his Master's Degree from MANIT, Bhopal, India in 1991. He received $\mathrm{PhD}$ from Andhra University in 2004.He has published over 100 research papers in refereed journals and conference proceedings.

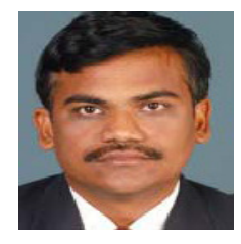

